\title{
Local well-posedness of compressible Radiation Hydrodynamic equations with density-dependent viscosities and vacuum
}

\author{
Hao $\mathrm{Li}^{1}$ and Yachun $\mathrm{Li}^{1}$ \\ ${ }^{1}$ Shanghai Jiao Tong University
}

May 23, 2020

\begin{abstract}
In this paper, we consider the Cauchy problem for three-dimensional isentropic compressible radiation hydrodynamic equations with density-dependent viscosity coefficients. When the viscosity coefficients are given as power of density $(\$ \backslash$ rho^ $\backslash$ delta $\$$ with $\$ \backslash$ delta $>1 \$$ ), we establish the local-in-time existence of classical solutions containing a vacuum for large initial data. Here, we point out that the initial layer compatibility conditions are not necessary.
\end{abstract}

\section{Hosted file}

Local well-posedness of compressible radiation hydrodynamic equations with density-dependent visocositi available at https://authorea.com/users/325533/articles/453525-local-well-posedness-ofcompressible-radiation-hydrodynamic-equations-with-density-dependent-viscosities-andvacuum 